\title{
Post Heat Treatment of Plasma Sprayed Pure and Alumina-Titania Reinforced Hydroxyapatite Coating on SS 304 Steel
}

\author{
Gurbhinder Singh*, Surendra Singh, Satya Prakash
}

Metallurgical and Materials Engineering Department, Indian Institute of Technology, Roorkee 247667, India

* Corresponding author: gurbhinder@yahoo.com, Tele. +91-9458118766, fax +91-1332-273560,

\begin{abstract}
It has been reported by previous research work that in plasma spray process hydroxyapatite decomposes into some amorphous phases due to rapid cooling of the coated substrate during the coating process, which causes instability of coated implant. Post coating heat treatment has been expected to minimize these phases and also enhance the long term reliability of hydroxyapatite coatings on metal substrates. In this paper post coating heat treatment is carried out at different temperatures suggested by the literature to study its effect on the microstructural and mechanical properties of coating. Coated substrates were characterized by X-ray diffraction (XRD) and SEM/EDAX analysis.
\end{abstract}

Keywords: Hydroxyapatite, Post Heat Treatment, Amorphous Phases, Plasma Spray

\section{INTRODUCTION}

In recent years Hydroxyapatite (HA) coated metallic implants are recognized as one of the promising implant materials for load bearing conditions like hip and knee prosthesis [1]. HA coated metallic implants have favorable osto-conductivity due to ceramic HA coating and superior mechanical properties due to metallic substrate. For the bio medical applications the crystallinity of Hydroxyapatite (HA) coating should be of high degree to ensure low dissolution rates in vitro [2-4]. Plasma spray technique is the only process which is clinically recommended by Food and Drug Administration (FDA), USA due to unmatchable properties of coating obtained by this process among other coating techniques [5]. But there are some problems which are associated with this process. First is that during coating process rapid cooling of coated 
substrates leads to formation of some amorphous phases like try-calcium phosphate ( $\alpha$ and $\beta$ TCP) and tetra- calcium phosphates (TTCP) [6]. These phases are rapidly soluble in human blood plasma and can cause implant instability after some time of implantation [7-9]. These phases must be eliminated or minimized to prolong applications of bio implant. It has been observed by previous research work that pure HA coating has poor mechanical properties like Young's modulus, micro hardness and adhesion to substrate [10-11]. Another controversy regarding HA coated implant is its long term effectiveness in human body environment [7-9]. Lot of research work has been carried out to increase the effectiveness of the coating by optimizing coating parameters, reinforcing some secondary materials and by post coating heat treatment process [12-16]. It is reported in the previous literature that post coating heat treatment eliminates all non favorable phases formed during coating operation [17-18]. Khor and Cheang [19] suggested that post heat treatment also plays important role to enhance mechanical properties of HA coating. Furthermore Lue et al [20-21] observed some ultrafine particles after post coating heat treatment which may be the cause of improvement in mechanical properties of coating.

\section{MATERIALS AND METHOD}

Commercially available surgical stainless steel grade (SS-304L) having thickness $6 \mathrm{~cm}$ was used as substrate material. The composition of substrate material was checked by Optical Emission Spectrometer (Thermo Jarrell F., UK). Compositions provided by the industry and calculated in laboratory are shown in Table I.

Table I: Composition of Substrate Material

\begin{tabular}{|c|c|c|c|c|c|c|c|c|c|c|}
\hline Element & $\mathrm{C}$ & $\mathrm{Si}$ & $\mathrm{Mn}$ & $\mathrm{Cr}$ & $\mathrm{Ni}$ & $\mathrm{P}$ & $\mathrm{S}$ & $\mathrm{Cu}$ & $\mathrm{Mo}$ & $\mathrm{Fe}$ \\
\hline $\begin{array}{c}\text { \%age } \\
\text { (Provided) }\end{array}$ & $0.02-$ & $0.25-$ & $1.0-$ & $18-20$ & $8-12$ & $\begin{array}{c}0.03- \\
0.05\end{array}$ & $\begin{array}{c}0.01- \\
0.03\end{array}$ & --- & --- & Balance \\
\hline $\begin{array}{c}\text { \%age } \\
\text { (Calculated) }\end{array}$ & 0.0260 & 0.03505 & 2.20 & 19.46 & 7.082 & --- & --- & 0.4780 & 0.2048 & Balance \\
\hline
\end{tabular}

For pure HA coating commercially available HA powder having size in range of 100-180 $\mu \mathrm{m}$ was used. For reinforcement of coating 10\% (80 alumina-20 titania) having size in the range of $10-40 \mu \mathrm{m}$ was added by weight. SEM micrograph of pure HA, reinforce materials and reinforced HA are shown in the Fig.1(a), 1(b), 2(a), 2(b) and 3(a), 3(b) at different magnifications. It can be seen from the SEM micrographs 1(a) and 2(b) that both HA and reinforced materials have angular shape. At higher magnification it is revealed from the micrograph 1(b) that HA grain is made of very small particles. 


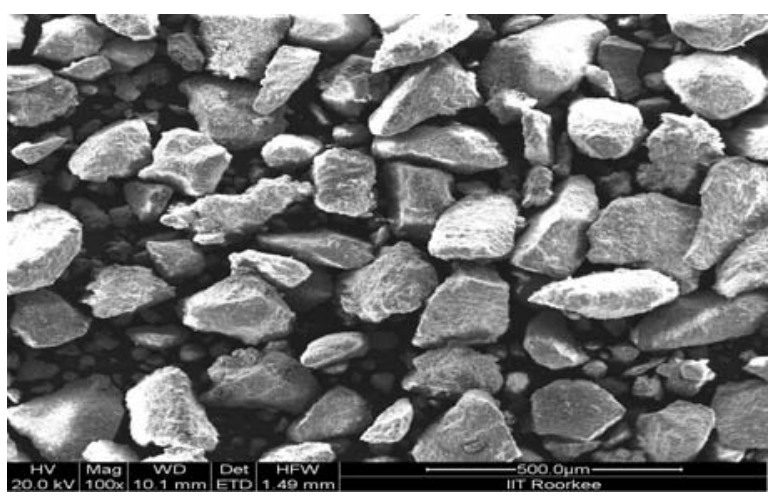

1(a) Pure HA at Magnification 100X

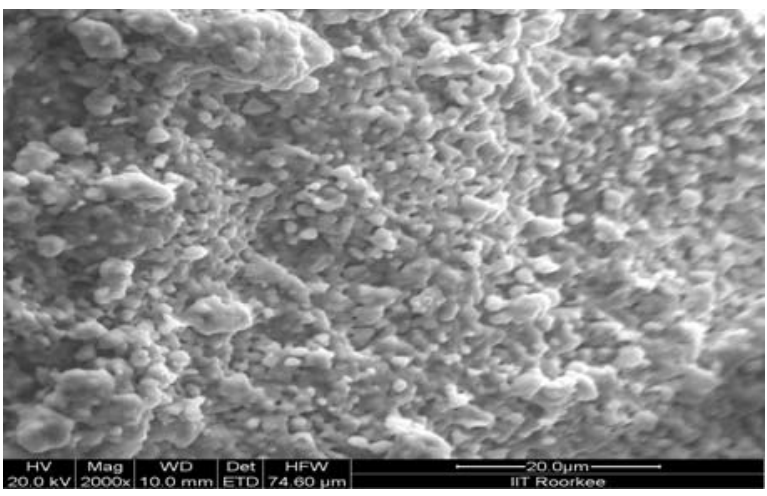

1(b) Pure HA at Magnification 2000 X

Fig.1 SEM Micrograph of Pure HA

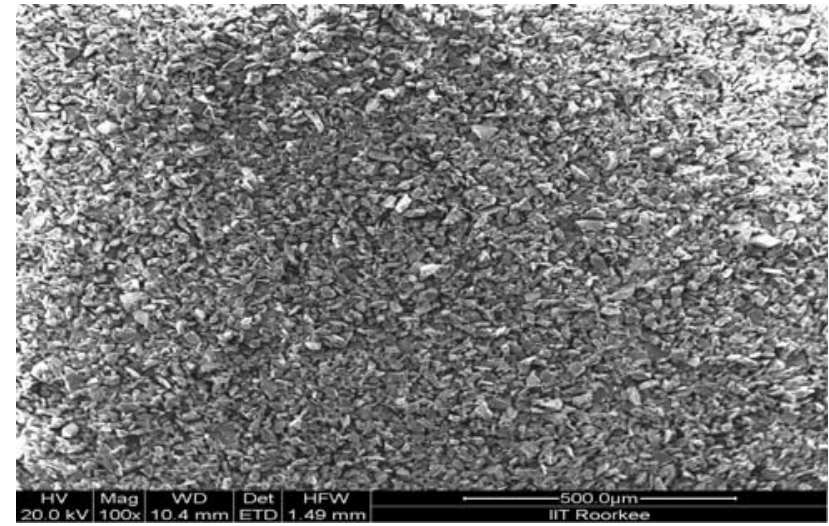

2 (a) Reinforce Material at Mag. 100X

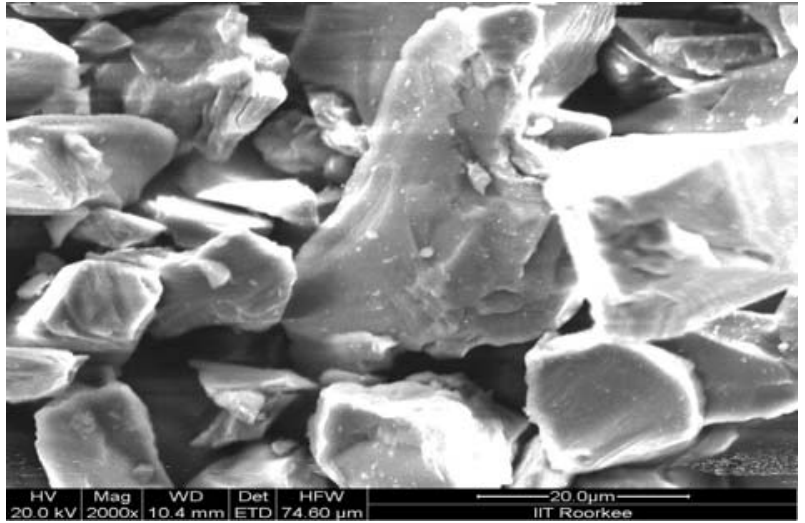

2(b) Reinforce Material at Mag. 2000X

Fig. 2 SEM Micrograph Reinforcing Material (80Alumina-20Titania)

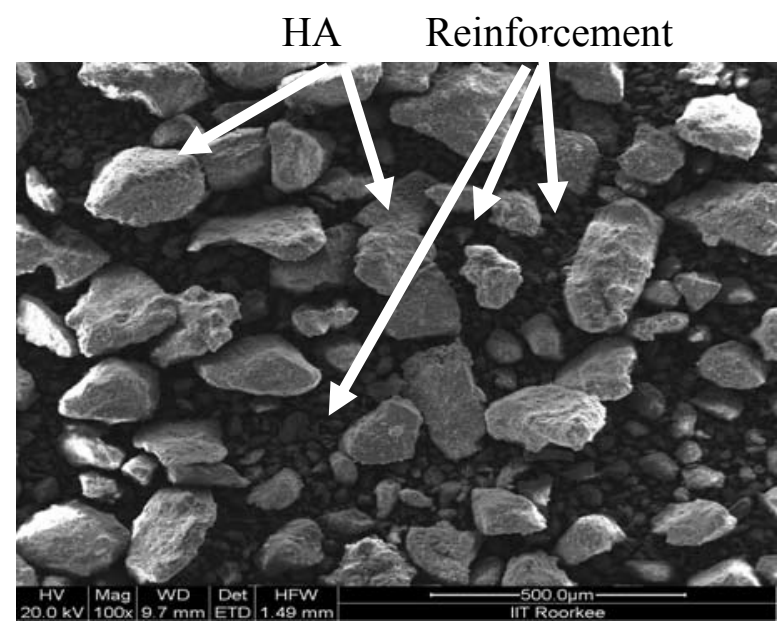

3 (a) Reinforced HA at Mag. 100X

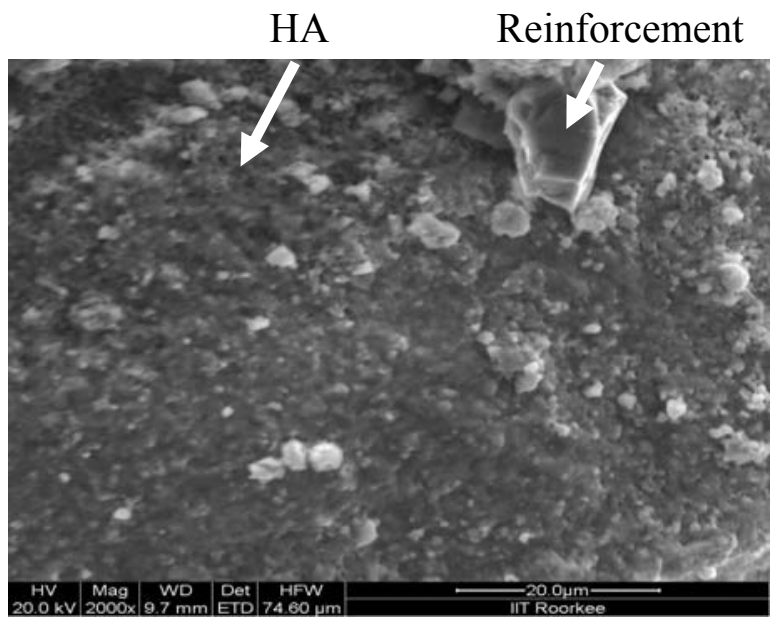

3(b) Reinforced HA at Mag. 2000X

Fig.3 SEM Micrograph of Reinforced HA 
Both coatings i.e. pure and reinforced HA were successfully deposited by Jet Air Plasma Spray Technique at Anod Plasma Spray Limited, Kanpur (India). The substrate material were cut into desired shape i.e. $20 \times 15 \times 5 \mathrm{~cm}$ and $10 \times 15 \times 5 \mathrm{~cm}$ then washed by acetone and dried in ordinary oven. Samples were grit blasted by alumina having size $350-450 \mu \mathrm{m}$ followed by air blasting to remove the alumina from the substrate surface just before coating. Coating parameters are given in Table II.

Table II Spraying parameters of pure and reinforced HA coating

\begin{tabular}{|l|l|l|}
\hline S.No & Coating Parameter & Units \\
\hline 1 & Current (A): & 750 \\
\hline 2 & Voltage (V): & 50 \\
\hline 3 & Arc Pressure (PSI): & 60 \\
\hline 4 & Powder Pressure (PSI): & 80 \\
\hline 5 & Hopper RPM: & 5.4 \\
\hline 6 & Hydrogen Pressure (PSI): & 10 \\
\hline 7 & Stand of Distance (mm): & 105 \\
\hline 8 & Powder Rate g/min: & 35 \\
\hline 9 & Plasma Gun diameter (mm): & 7 \\
\hline
\end{tabular}

As sprayed pure and reinforced HA coated samples were heat treated at $700{ }^{\circ} \mathrm{C}$ and $800{ }^{\circ} \mathrm{C}$ to evaluate the role of heat treatment process on coating properties. Samples were placed in the furnace as shown in the Fig. 4 and were heated to desired temperatures i.e. $700{ }^{\circ} \mathrm{C}$ and $800{ }^{\circ} \mathrm{C}$ at the rate of $5{ }^{\circ} \mathrm{C} / \mathrm{min}$. respectively. After attaining the desired temperature samples were heated for 2 hours. After two hours the furnace was switched off and samples were allowed to cool in the furnace for 8-10 hours for annealing. 


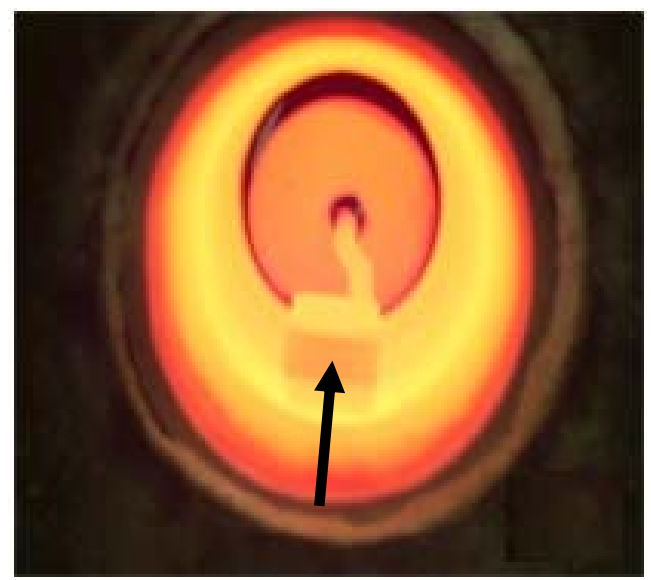

Coated sample inside the furnace

Fig. 4 Experimental set up of the furnace for post coating heat treatment process

X-Ray diffraction analysis was carried out to characterize as sprayed and sintered samples to reveal the effect of post coating heat treatment. $\mathrm{Cu}$ target was used for analysis at speed $2 \% \mathrm{~min}$ in the range of $10-90^{\circ}$ at $2 \theta$ angle. SEM/EDAX (FEI Quanta 200F, Made in Czech Republic) analysis was carried out to check the morphology of as sprayed and sintered coated samples. Surface roughness $(\mathrm{Ra})$ values of the coated samples were carried out by surface roughness tester (Wyko NT 1100, USA). Each reported value of surface roughness ( $\mathrm{Ra}$ ) is the mean of five observations taken at different locations. Each value of $\mathrm{R}_{\mathrm{a}}$ is the average roughness calculated over the entire measurement array given as $\mathrm{R}_{\mathrm{a}}=\frac{\mathbf{1}}{\boldsymbol{M}} \sum_{J=1}^{M}\left\{\mathrm{Z}_{\mathrm{j}}\right\}$ Where $\mathrm{Z}_{\mathrm{j}}$ is the height of each pixel after the zero is removed.

To check the micro hardness of coatings, the coated samples were cut through cross-sectional and mounted in epoxy and polished on various grade emery papers like 1/0, 2/0, 3/0, 4/0, 5/0 and then cloth polishing with alumina paste grade II. Micro Hardness Tester (Leitz, Germany) fitted with a Vickers pyramidal diamond indenter was used for this test. $10 \mathrm{gm}$ load was applied to check the hardness. Hardness value was calculated from the relation $\mathrm{H}_{\mathrm{v}}=1854.4 * \mathrm{~F} / \mathrm{d}^{2}$. Where $\mathrm{F}$ is for load in grams and $d$ is for the diameter of the indenter in micrometer. Each reported value of the micro hardness is the average value of five measurements

Zeiss Axiovert 200 MAT inverted optical microscope, fitted with imaging software Zeiss Axiovision Release 4.1, (Germany) was used to determine the porosity of the as sprayed and post coating heat treated samples, which is compatible with ASTM B276 standard. Porosity was measured by colour contrast method. About 20 readings were taken to avoid overlap between two locations. 


\section{RESULTS}

SEM micrographs of as sprayed pure HA coating, post heat treated coating at $700^{\circ} \mathrm{C}$ and $800^{\circ} \mathrm{C}$ are shown in Fig 5(a), 5(b) and 5(c) respectively. It can be seen from the SEM micrograph 5(a) that coating is uniform however few unmelted grains may be observed in as spray coating which are not present in post coating heat treated coatings at $700^{\circ} \mathrm{C}$ and $800^{\circ} \mathrm{C}$ as shown in $5(\mathrm{~b})$ and 5 (c). This may be due to recrytallization of coating during heat treatment. Similar observations were reported by previous research work [16, 21]. Coating tends to become denser in case of post heat treated coatings.

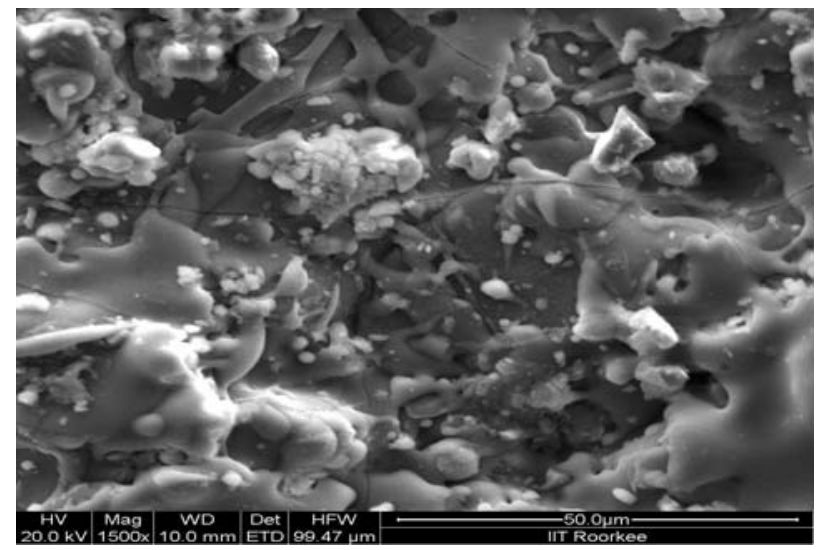

$5(\mathrm{a})$

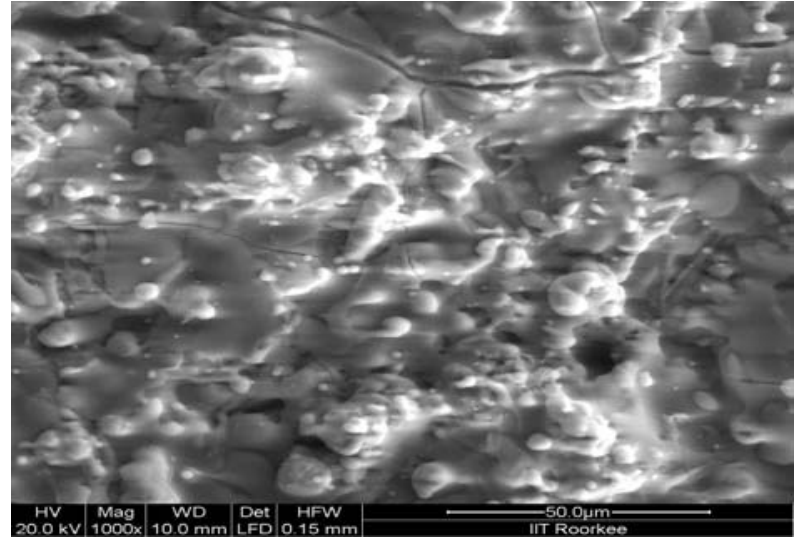

$5(b)$

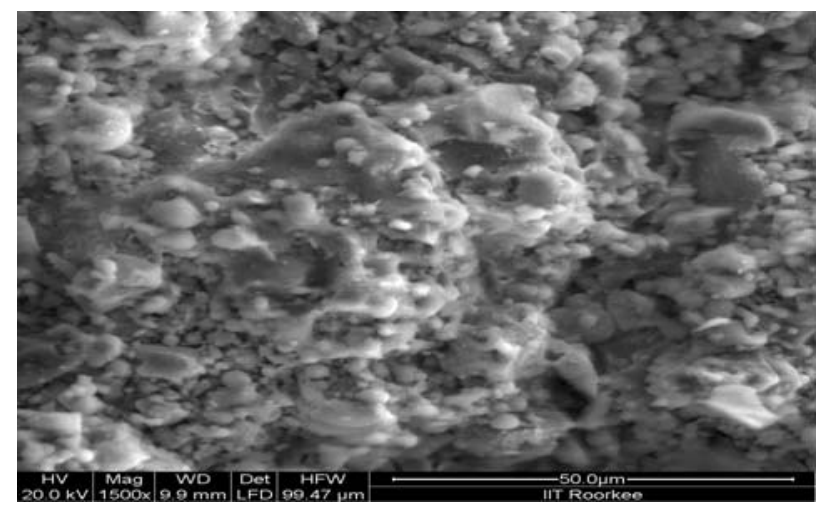

$5(\mathrm{c})$

Fig. 5 SEM micrograph of as sprayed pure HA coating 5(a), post coating heat treated coating at $700^{\circ} \mathrm{C} 5(\mathrm{~b})$ and $800^{\circ} \mathrm{C} 5(\mathrm{c})$

Similarly in case of reinforced HA coatings, as sprayed, post heat treated coatings at $700^{\circ} \mathrm{C}$ and $800^{\circ} \mathrm{C}$ are shown in Fig. 6(a) ,6(b) and 6(c) respectively. Here also continuous coating with few un melted grains may be seen from Fig 6(a).Fig.6 (b) shows almost all grains fully melted. In Fig. 6(c) it can be seen that coating becomes comparatively denser. This may be due to recrystallization of coating during heat treatment process. 


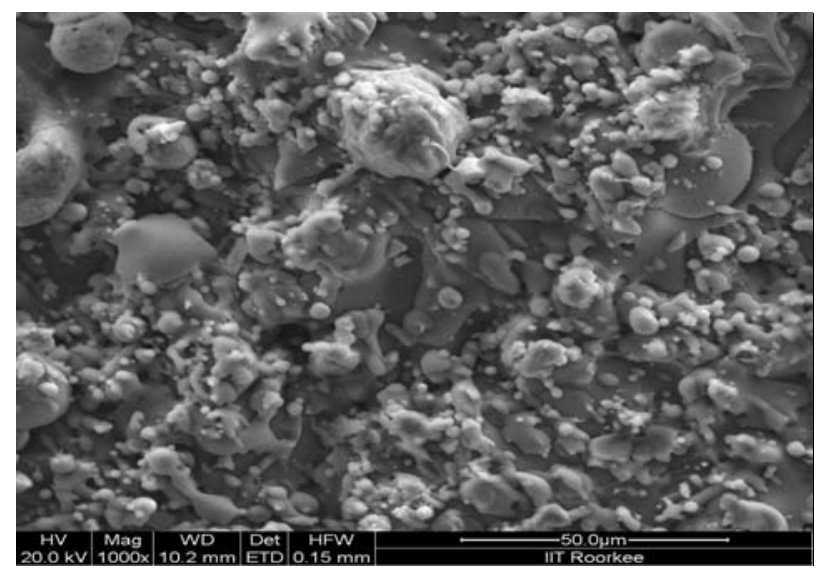

6(a)

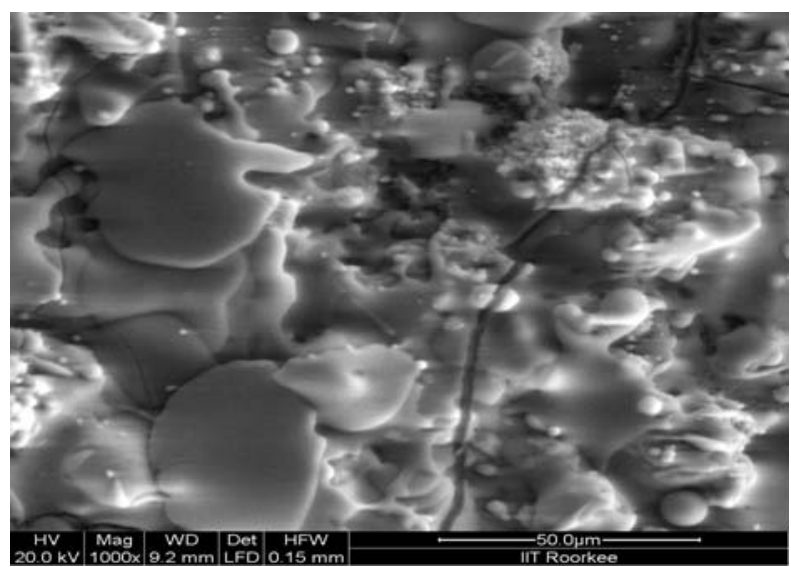

$6(b)$

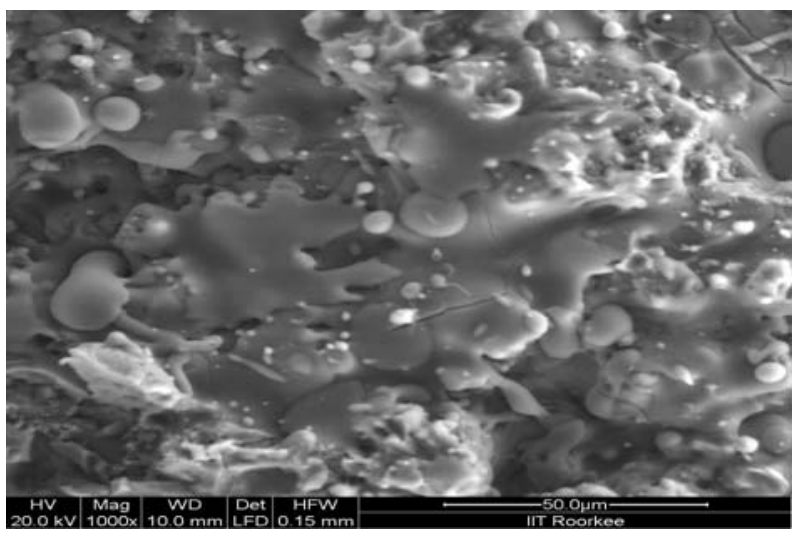

6(c)

Fig. 6 SEM micrograph of as sprayed reinforced HA coating 6(a), post coating heat treated coating at $700^{\circ} \mathrm{C} 6(\mathrm{~b})$ and $800^{\circ} \mathrm{C} 6(\mathrm{c})$

$\mathrm{X}$-Ray diffraction analysis of pure and reinforced HA powders, as sprayed coatings, post heat treated coatings at $700{ }^{\circ} \mathrm{C}$ and $800{ }^{\circ} \mathrm{C}$ are shown in Fig. 7(a) and 7(b). Analysis shows that non amorphous phases like tri calcium phosphates ( $\alpha$-TCP. B-TCP) and tetra calcium phosphate (TTCP) are observed between $31^{\circ}$ to $33^{\circ}$ are present in both as sprayed pure and reinforced coatings which were not present in their original powders before coatings. Similar phases were reported by previous research work [11, 12, and 22]. These phases were successfully eliminated by post heat treatment process at $700{ }^{\circ} \mathrm{C}$ and $800{ }^{\circ} \mathrm{C}$. 


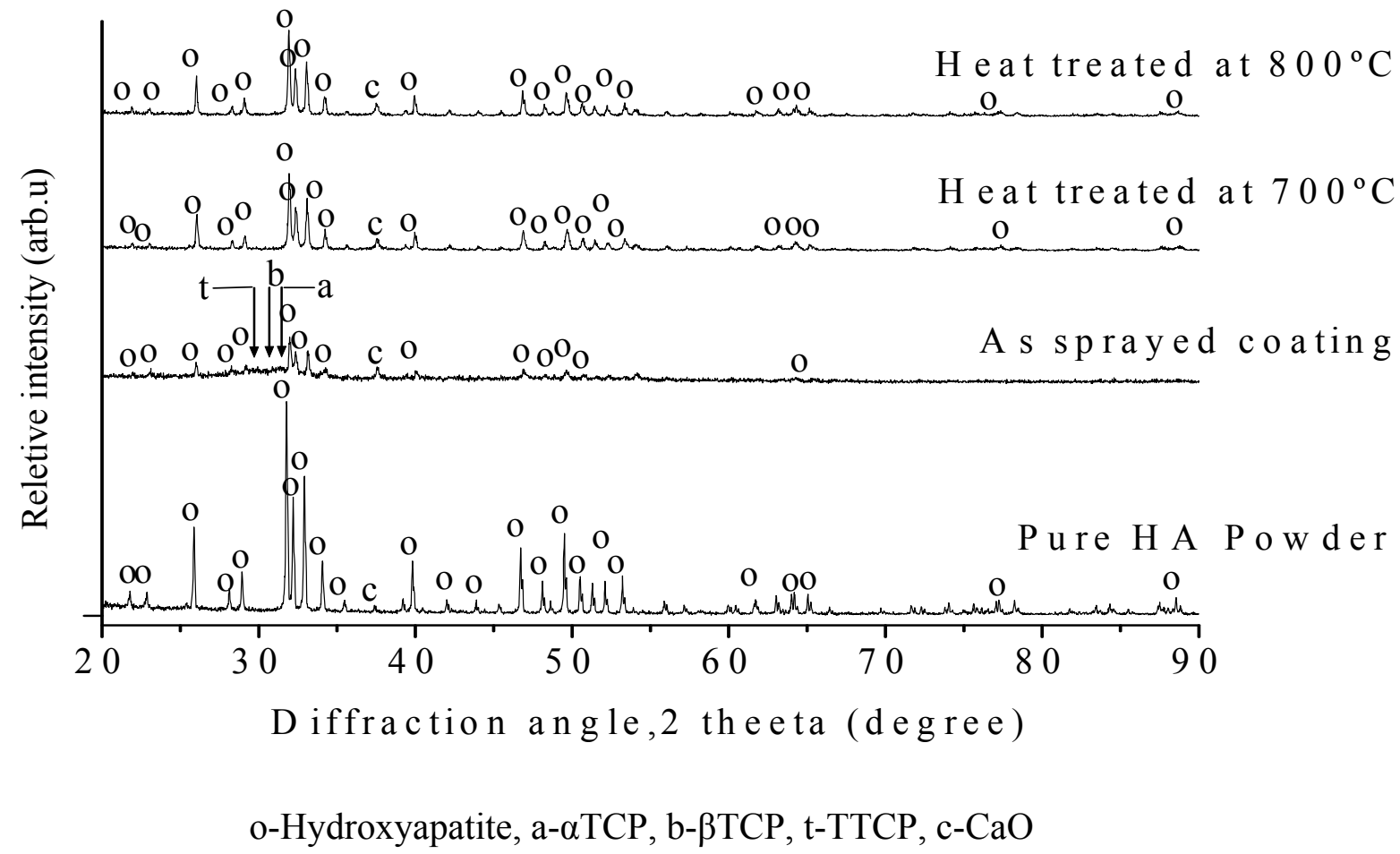

Fig 7 (a) XRD analysis of pure $\mathrm{HA}$ powder, as sprayed coating and heat treated coatings at $700^{\circ} \mathrm{C}$ and $800^{\circ} \mathrm{C}$

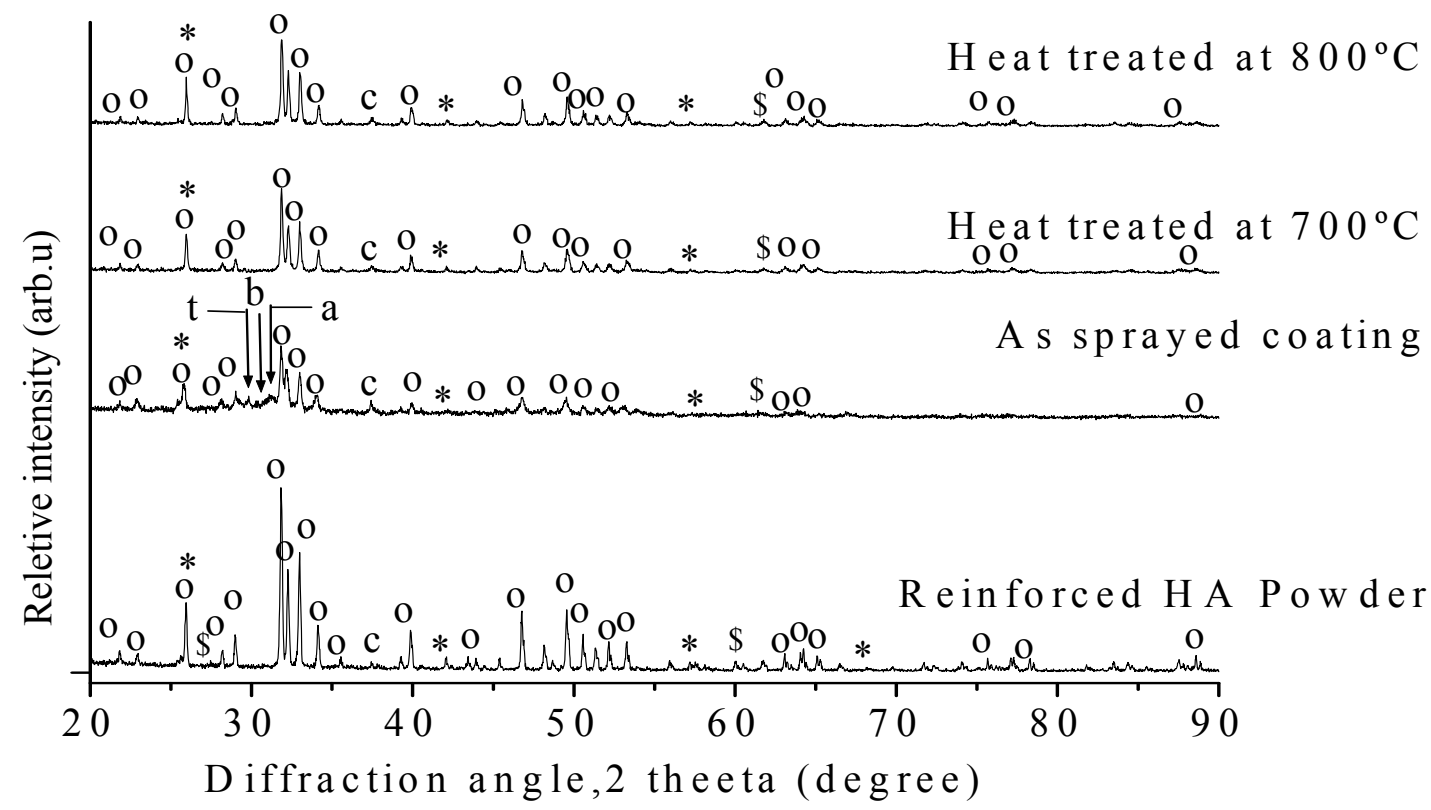

o-Hydroxyapatite, a- $\alpha$ TCP, b- $\beta$ TCP, t-TTCP, c-CaO, ${ }^{*}-\mathrm{Al}_{2} \mathrm{O}_{3}, \$-\mathrm{TiO}_{2}$

Fig 7 (b) XRD analysis of reinforced HA powder, as sprayed coating and heat treated coatings at $700^{\circ} \mathrm{C}$ and $800^{\circ} \mathrm{C}$ 
Surface roughness of the coating is very important for bio implant applications. Coating must be sufficiently rough to facilitate the cell growth in the body environments. Surface roughness of as sprayed pure HA and reinforced HA, post heat treated pure and reinforced HA coatings at $700^{\circ} \mathrm{C}$ and $800^{\circ} \mathrm{C}$ temperatures is shown in the Fig.8. Surface roughness of the reinforced as sprayed HA coating is slightly higher than that of pure HA coating. That may be due to the role of reinforcement. Post heat treatment process results in reduction in surface roughness in case of both pure and reinforced HA coatings. This may be due to refinement of grains due to sintering process.

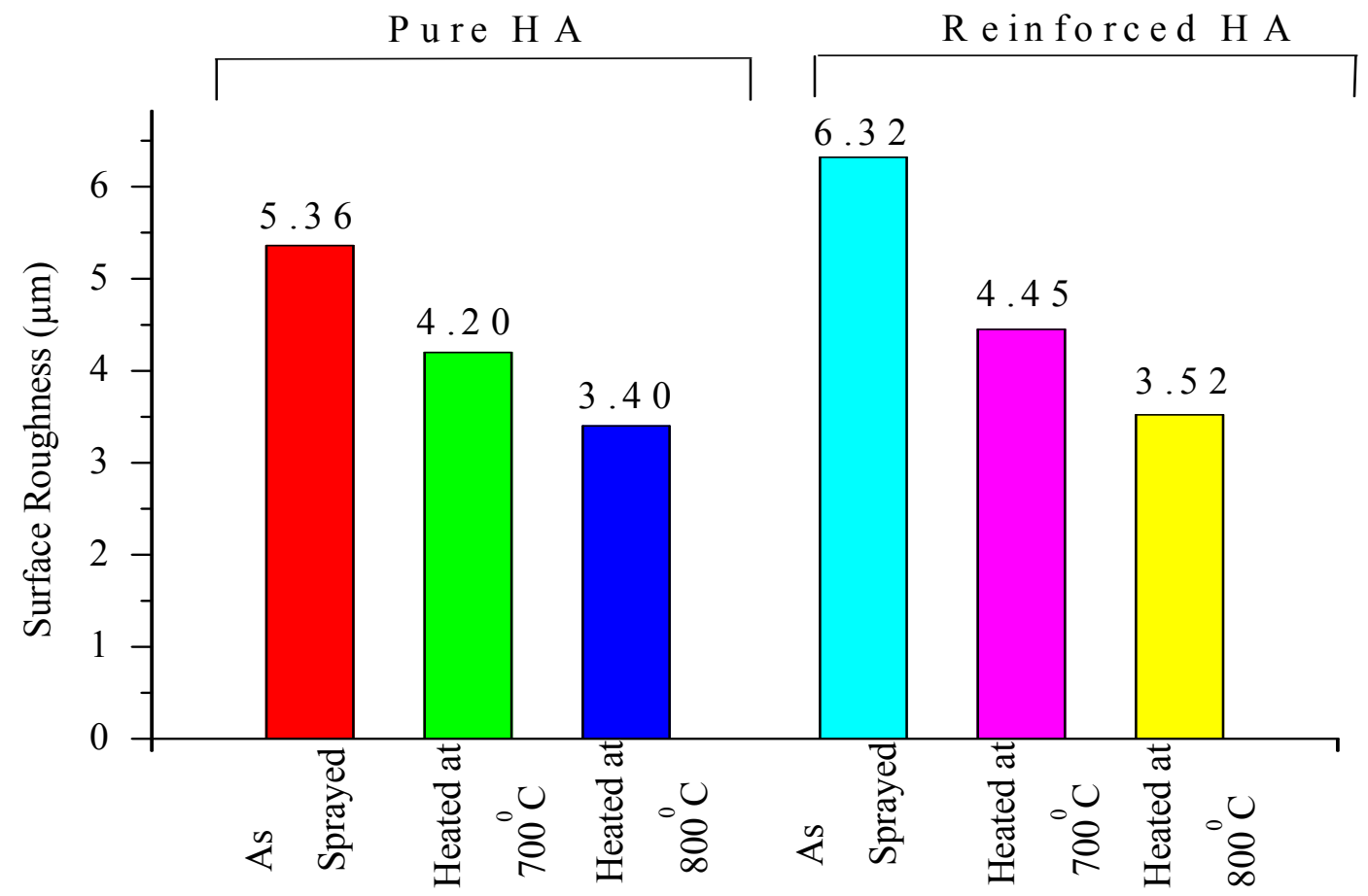

Fig.8 Surface roughness of pure and reinforced as sprayed and post heat treated HA coating at $700^{\circ} \mathrm{C}$ and $800^{\circ} \mathrm{C}$ temperature

Micro hardness is an important property for a bio implant material. For trouble free long service of coated bio implant in body it must possess sufficient hardness so that it may withstand the high stresses in high load bearing conditions like hip and knee prosthesis. Micro hardness of as sprayed pure and reinforced HA coatings and post treated pure and reinforced coatings at $700^{\circ} \mathrm{C}$ and $800^{\circ} \mathrm{C}$ temperatures are shown in Fig.9.It can be observed that with reinforcement hardness is slightly increased. Post coating heat treatment also has a positive impact on improvement of microhardness. This improvement in hardness may be attributed to recrystallization of the coatings due to heat treatment. 


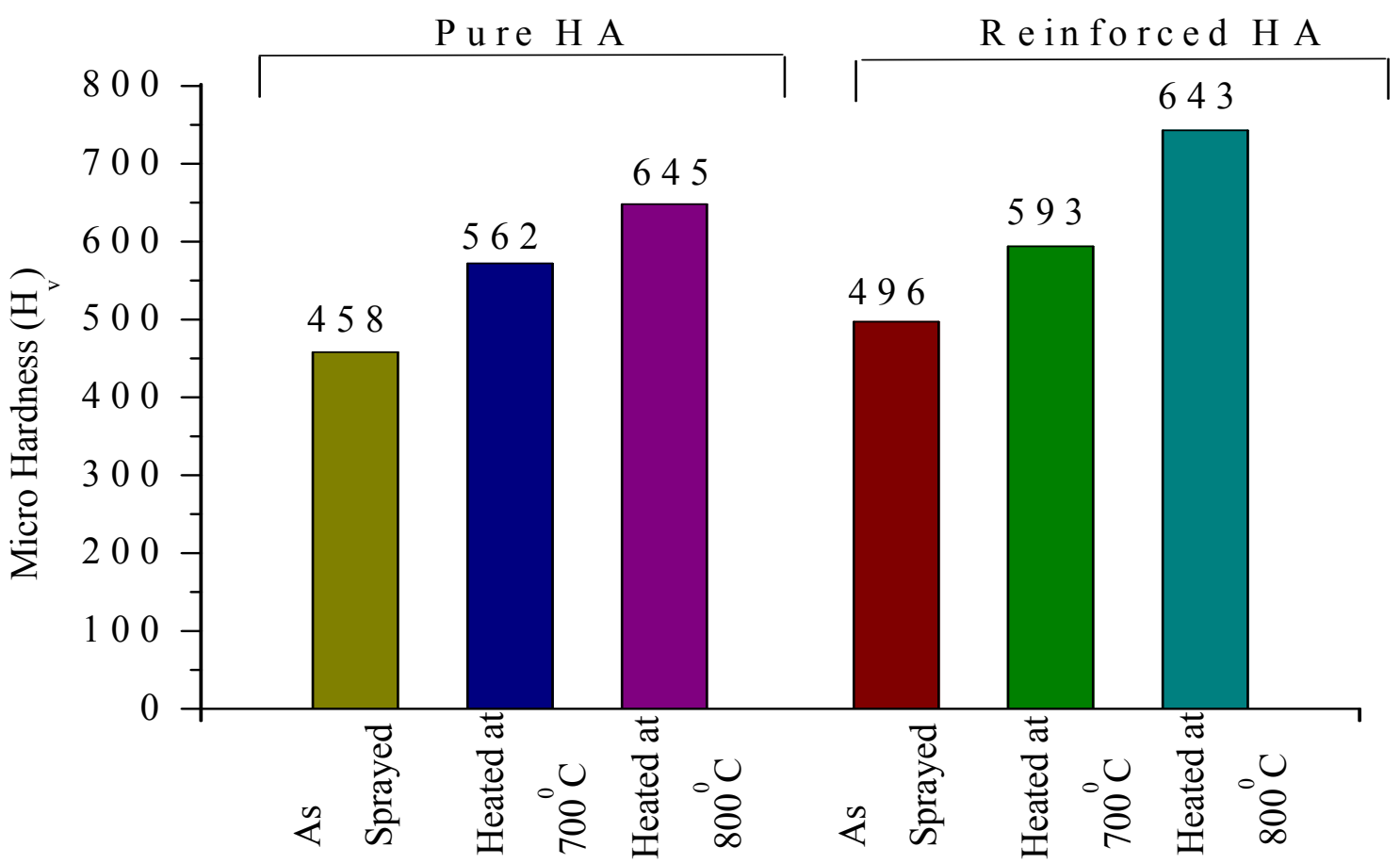

Fig.9 Micro hardness of pure and reinforced as sprayed and post heat treated HA coating at $700^{\circ} \mathrm{C}$ and $800^{\circ} \mathrm{C}$ temperature

Porosity of pure as sprayed HA coating is in the most promising range i.e. less than $2 \%$. Reinforcement has reduced the porosity slightly. Whereas post coating heat treatment led reduction in porosity less than $1 \%$.Which may attribute refinement of grains.

\section{CONCLUSIONS}

Pure and 10\% wt (80 alumina-20 titaina) reinforced HA coatings were successfully deposited on SS-304 steel substrate by plasma spray process. Post coating heat treatment was carried out at $700^{\circ} \mathrm{C}$ and $800^{\circ} \mathrm{C}$ temperature. Following conclusions may be drawn from the study:-

1. Improvement in microhardness and surface roughness was observed with the reinforcement with slight decrease in porosity.

2. Some non favorable amorphous phases were observed in both pure and reinforced as sprayed coatings which were not present in their original powders.

3. These phases were successfully eliminated by post coating heat treatment at $700^{\circ} \mathrm{C}$ and $800^{\circ} \mathrm{C}$ temperatures. 
4. With elimination of amorphous phases the post heat treatment process had also improved the mechanical and microstructural properties like micro hardness and porosity of both pure and reinforced HA coatings with slight decrease in surface roughness.

5. Few un melted grains of HA was observed in both as sprayed pure and reinforced HA coatings which were eliminated by recrystallization during post coating heat treatment process.

\section{REFERENCES}

[1] L. Claes,H.J. Wilke, H. Kiefer, A. Meschenmoser, 1990, Handbook of Bioactive Ceremics, Vol. II, CRC Press, Boca Raton, pp. 77-80.

[2] R.L. Salsbury, 1991, "Quality control of hydroxyapatite coatings: purity and crystallinity determinations", National Thermal Spray Conf. ASM Int. pp. 471-473.

[3] Lugcheider E, Knepper M, Heimberg B, 1994, "Cytotoxicity investigation of plasmasprayed calcium phosphate coatings", Journal of Materials Science: Materials in Medicine, Vol. 5.pp. 371-375.

[4] Frayssinet P, Tourenne F, Rouquet N, Conte P, Delga C, Bonel G., 1994, "Comparative biological properties of HA plasma-sprayed coatings having deferent crystallinities", Journal of Materials Science: Materials in Medicine, Vol. 5.pp. 11-17.

[5] Kantesh Balani, Yao Chen, Sandip P. Harimkar, Narendra B. Dahotre, Arvind Agarwal, 2007,"Tribological behavior of plasma-sprayed carbon nanotube-reinforced hydroxyapatite coating in physiological solution”, Acta Biomaterialia ,Vol. 3,pp. 944951.

[6] M.F Morks, Akira Kobayashi, 2006, "Influence of gas flow rate on the microstructure and mechanical properties of hydroxyapatite coatings fabricated by gas tunnel type plasma spraying, Surface and Coatings Technology", Vol. 201, pp. 2560-2566.

[7] Yu-Peng Lu, Gui-Yong Xiao, Shi-Tong Li, Rui-Xue Sun, Mu-Sen Li,2006, "Microstructural inhomogeneity in plasma-sprayed hydroxyapatite coatings and effect of post-heat treatment", Applied Surface Science, Vol. 252,pp. 2412-2421.

[8] W.F. Morris, 1998, "Hydroxyapatite-coated implants: a case for their use", J. Oral Maxillofac. Surg., Vol. 56 (II), pp. 1303-1311.

[9] T. Albrektsson, 1998, "Hydroxyapatite-coated implants: a case against their use", J. Oral Maxillofac. Surg., Vol. 56 (II), pp. 1312-1326.

[10] L. Fu, K.A. Khor, J.P. Lim, 2001, "Processing, microstructure and mechanical properties of yttria stabilized zirconia reinforced hydroxyapatite coatings", Materials Science and Engineering A, Vol.316, pp.46-51

[11] M.F. Morks, 2008, "Fabrication and characterization of plasma - sprayed $\mathrm{HA} / \mathrm{SiO}_{2}$ coatings for biomedical application", Journal of the mechanical Behaviour of Biomedical Materials, Vol. 1, pp. 105-111. 
[12] M.F. Morks and Akira Kobayashi, 2007, "Effect of gun current on the microstructure and crystallinity of plasma sprayed Hydroxyapatite coating", Applied Surface Science, Vol. 253, pp. 7136-7142.

[13] Zheng XB, Huang MH, Ding CX, 2000, "Bond strength of plasma sprayed hydroxyapatite/Ti composite coatings", Biomaterials, Vol. 21 (8), pp. 841-849.

[14] Lei Fu, Khiam Aik Khor, Joo Peng Lim, 2006, "Yttria stabilized zirconia reinforced hydroxyapatite coatings", Surface and Coatings Technology, Vol. 27, pp. 66-75.

[15] Huaxia Ji, P.M.Marquis, 1993, "Effect of heat treatment on the microstructure of plasmasprayed hydroxyapatite coating" Biomaterials, Vol. 14,No. 1,pp.64-68.

[16] Yu Peng Lu, Yi Zhong Song, Rui Fu Zhu, Mu Sen Li, Ting Quan Lei, 2003, “ Factors influencing phase compositions and structure of plasma sprayed hydroxyapatite coatings during heat treatment" Applied Surface Science,Vol.206,pp. 345-354.

[17] Shinn-jyh Ding, Tsui-hsien Huang, Chia-tze Kao, 2002, "Immersion behavior of plasma sprayed modified hydroxyapatite coatings after heat treatment", Surface and Coatings Technology, Vol. 165, pp. 248-257.

[18] Zhao Guo-liang, Wen Guang-wu, Wu Kun, 2009, "Influence of processing parameters and heat treatment on phase composition and microstructure of plasma sprayed hydroxyapatite coatings", Trans. Nonferrous Met. Soc. China, vol.19, pp. 463- 469.

[19] H. Li,K.A. Khor, P. Cheang, 2002, " Properties of heat treated calcium phosphate coatings deposited by high velocity oxy fuel (HVOF) spray", Biomaterials,Vol.23,pp. 2105-2112.

[20] Yu Peng Lu, Yi Zhong Song, Rui Fu Zhu, Mu Sen Li, Ting Quan Lei, 2003, “ Factors influencing phase compositions and structure of plasma sprayed hydroxyapatite coatings during heat treatment" Applied Surface Science,Vol.206,pp. 345-354.

[21] Yu Peng Lu, S.T.Li, Rui Fu Zhu, Mu Sen Li, Ting Quan Lei, 2002, "Recrrystallinzation and structure of plasma sprayed hydroxyapatite coating", Chin. J. Inorg. Chem.Vol. 18, pp. 844-848.

[22] Wenxiu Que, K.A. Khor, J.L. Xu, L.G. Yu, 2008, "Hydroxyapatite/titania nanocomposites derived by combining high-energy ball milling with spark plasma sintering processe", Eur. Ceram. Soc., Vol.28, pp.3083-3090. 